\title{
EVALUASI PENERAPAN INTERNAL CONTROL DAN PELAKSANAAN GOOD CORPORATE GOVERNANCE PADA PT PLN (PERSERO) DISTRIBUSI JAKARTA RAYA DAN TANGERANG
}

\author{
Iswandi \\ Jurusan Akuntansi, Fakultas Ekonomi dan Bisnis, Universitas Bina Nusantara \\ Jl. K.H. Syahdan No. 9, Palmerah, Jakarta Barat 11480 \\ iswandi@binus.ac.id
}

\begin{abstract}
PT. PLN (Persero) Distribusi Jakarta Raya dan Tangerang have implemented Internal Control and Good Corporate Governance. The research would like to evaluate the implementation of Internal Control accordance with COSO's criteria (Committee of Sponsoring Organizations of the Treadway Commission) and KNKG's criteria (Komite Nasional Kebijakan Governance). Based on research found that five components of COSO such as control environment, risk assessment, control activities, information and communication, monitoring have been implemented but unfortunately one of the component such as control activities not yet implemented properly accordance with COSO's criteria. The company also have been imlemented GCG accordance with KNKG's criteria but still need development through internalization GCG's spirit among the employees because some employees still have different perception related to GCG. For example from employee stand point there's no problem receive special gift or receive special payment from customer and have a conflict of interest when deal with public accountant.
\end{abstract}

Keywords: Internal Control, Good Corporate Governance, COSO, KNKG

\begin{abstract}
ABSTRAK
PT PLN (Persero) Distribusi Jakarta Raya dan Tangerang menerapkan Internal Control dan Good Corporate Governance sehingga perlu dilakukan analisa dan evaluasi untuk mengetahui apakah pelaksanaannya sesuai dengan kriteria COSO (Comittee of Sponsoring Organizations of The Treadway Commission) dan KNKG (Komite Nasional Kebijakan Governance). Dari evaluasi yang dilakukan diketahui bahwa lima komponen Internal Control yang ditetapkan COSO telah diimplementasikan namun salah satu komponen Internal Control yaitu aktivitas pengendalian belum sesuai pelaksanaannya dengan kriteria yang ditetapkan COSO. Sedangkan pelaksanaan GCG telah dilaksanakan dengan baik.
\end{abstract}

Kata kunci: Internal Control, Good Corporate Governance, COSO, KNKG 


\section{PENDAHULUAN}

Good Corporate Governance (GCG) merupakan salah satu kunci sukses perusahaan untuk tumbuh dan menguntungkan dalam jangka panjang, sekaligus memenangkan persaingan bisnis global, terutama bagi perusahaan yang sedang berkembang apalagi bagi perusahaan yang terdaftar di bursa saham. Corporate governance merupakan suatu cara untuk menjamin bahwa manajemen bertindak yang terbaik untuk kepentingan Stakeholders. Selain itu pelaksanaan GCG menuntut adanya perlindungan yang kuat terhadap hak-hak pemegang saham, terutama pemegang saham minoritas.

Internal Control (IC) merupakan suatu teknik pengawasan yaitu pengawasan keseluruhan dari kegiatan operasi perusahaan, baik mengenai organisasinya maupun sistem atau cara-cara yang digunakan untuk menjalankan perusahaan dan juga alat-alat yang digunakan perusahaan. Tujuan internal control harus dipandang dari orang yang melaksanakan internal control tersebut. Sistem harus dirancang sedemikian rupa sehingga para pegawai dapat merasakan sendiri dan yakin bahwa internal control dapat mengurangi kesulitan operasi dan melindungi perusahaan. Internal control harus selalu dimonitor dan dievaluasi agar manfaatnya senantiasa dapat dipertanggungjawabkan.

PT PLN (Persero) Distribusi Jakarta Raya dan Tangerang merupakan salah satu ujung tombak PLN dalam melayani pelanggan diwilayah DKI Jakarta. Untuk mempertahankan posisinya dan mencegah terjadinya kecurangan yang dilakukan oleh anggota organisasi, manajemen perusahaan harus mampu merencanakan internal control yang tepat dan menerapkannya di perusahaan, dan melaksanakan GCG di perusahaan tersebut.

Menurut COSO (Comittee of Sponsoring Organizations of the Treadway Commission), sistem pengendalian adalah suatu proses yang dipengaruhi oleh badan pengawas organisasi,manajemen,dan pegawai lainnya yang dirancang untuk memberikan keyakinan yang memadai tentang pencapaian tujuan dalam beberapa kategori yaitu efektivitas dan efisiensi kegiatan, kategori keandalan laporan keuangan dan kategori ketaatan dan kepatuhan pada hukum.

Tujuan perancangan dan pelaksanaan internal control menurut Arens, Elder \& Beasley (2003) adalah melakukan efisiensi dan efektivitas dari operasional, menjamin keandalan laporan keuangan dan kepatuhan terhadap hukum dan peraturan yang berlaku. Pengendalian yang dilakukan harus dapat mencegah pemborosan atau kegiatan yang tidak perlu dalam segala aspek usaha perusahaan serta mengamankan aktiva dan catatan akuntansi. Manajemen bertanggung jawab dalam menyiapkan laporan keuangan. Dengan demikian manajemen mempunyai kewajiban hukum dan profesional untuk menjamin bahwa informasi telah disiapkan sesuai dengan prinsip akuntansi yang diterima umum.

Menurut COSO yang dikutip oleh Boynton, Johnson \& Kell (2003), ada lima komponen internal control yaitu: (1) lingkungan pengendalian; (2) penilaian resiko; (3) informasi dan komunikasi; (4) aktivitas pengendalian; dan (5) pemantauan.

Lingkungan pengendalian merupakan pondasi dari semua komponen pengendalian intern lainnya yang menyediakan disiplin dan struktur. Lingkungan pengendalian dibentuk oleh integritas dan nilai etika dari manajer bisnis, kompetensi, tanggungjawab dan komposisi dewan direksi dan komite audit, gaya operasi manajemen, struktur organisasi yang dibentuk, penetapan wewenang dan tanggung jawab dan kebijakan SDM yang menjamin bahwa personel entitas memiliki tingkat integritas, nilai etika, dan kompetensi yang diharapkan.

Namun demikian internal control juga memiliki kelemahan, yaitu tidak dapat menjamin tidak akan terjadi kolusi, struktur senantiasa harus dirubah dan kompetensi staf pelaksana dan 
memperhatikan azas biaya dengan manfaat yang diharapkan. Pedoman umum GCG terdiri dari lima prinsip yaitu transparansi, akuntabilitas, responsibilitas, independensi, kewajaran dan kesetaraan. Masing-masing prinsip tersebut dilengkapi dengan pedoman pelaksanaan sebagai acuan dalam menerapkannya.

\section{METODE}

Penelitian dilakukan di PT PLN (Persero) distribusi Jakarta Raya dan Tangerang dengan ruang lingkup meliputi analisa internal control yang diterapkan perusahaan menggunakan kriteria COSO. Sedangkan evaluasi pelaksanaan GCG perusahaan menggunakan kriteria KNKG (Komite Nasional Kebijakan Governance).

Metode penelitian yang dilakukan adalah studi kepustakaan, analisa data primer berupa perencanaan dan penerapan internal control dan good corporate governance. Penarikan sampel menggunakan metode simple random sampling dengan cara menyebarkan 30 kuesioner kepada karyawan serta wawancara dengan karyawan perusahaan dan pihak-pihak yang berkepentingan di bidang internal control dan good corporate governance. Sebagai penunjang menggunakan data sekunder yang dapat dilihat di website perusahaan.

Tujuan penelitian adalah untuk evaluasi kualitas dan analisa pelaksanaan internal control dan GCG di perusahaan tersebut apakah telah dilaksanakan dengan baik sesuai dengan criteria yang ditetapkan COSO dan KNKG.

\section{HASIL DAN PEMBAHASAN}

\section{Evaluasi Kualitas dan Kesesuaian Internal Control dengan COSO}

Berdasarkan evaluasi, Internal Control perusahaan telah sesuai dengan kriteria COSO kecuali untuk aktivitas pengendalian. Hasil evaluasi dibagi dalam beberapa kriteria. Dalam kriteria 1: lingkungan pengendalian, internal control yang diterapkan perusahaan telah sesuai dengan kriteria COSO bahwa setiap perusahaan diharapkan mampu untuk merancang struktur organisasi yang baik, memberikan pekerjaan kepada karyawan sesuai dengan pengetahuan dan kemampuannya, sehingga para karyawan memahami tugas dan wewenangnya. Pemimpin perusahaan diharapkan untuk mampu menerapkan kode etik di perusahaan dan berusaha untuk mengkomunikasikan kepada seluruh karyawan, agar karyawan dapat memahami visi dan misi perusahaan, dan melaksanakan tugasnya dengan tanggung jawab.

Dalam kriteria 2: penilaian risiko, internal control yang diterapkan perusahaan telah sesuai dengan kriteria COSO bahwa tim manajemen resiko harus merancang sistem informasi dan pengendalian yang dapat mengurangi resiko. Jika manajemen mampu merancang dan mengimplementasikan pengendalian tersebut dengan baik, maka akan banyak resiko yang dapat dicegah.

Dalam kriteria 3: informasi dan komunikasi, internal control yang diterapkan perusahaan telah sesuai dengan kriteria COSO bahwa komunikasi berfungsi untuk memastikan bahwa setiap karyawan yang terlibat di kegiatan bisnis tersebut mampu memahami kegiatannya berhubungan dengan orang didalam maupun di luar perusahaan. Setiap perusahaan harus memiliki dokumen/informasi yang lengkap dan valid mengenai kegiatan bisnisnya dan harus menyampaikan 
informasi tersebut dengan melaksanakan komunikasi yang baik. Sehingga dapat diperoleh rincian yang mencukupi dari semua transaksi untuk memungkinkan penyajian yang tepat di laporan keuangan dan pengungkapan yang diperlukan.

Dalam kriteria 4: aktivitas pengendalian, internal control yang diterapkan perusahaan belum seluruhnya sesuai dengan kriteria COSO yang menetapkan bahwa dalam aktivitas pengendalian, perusahaan dapat melaksanakannya dengan cara pemisahan tugas, yaitu memastikan bahwa setiap karyawan tidak melakukan tugas yang tidak seimbang yang dapat mengakibatkan karyawan tersebut melakukan kekeliruan. Pengendalian juga dilakukan dalam penggunaan akses data dan pemrosesan informasi, yaitu kelengkapan, otorisasi, dan akurasi transaksi.

Yang terjadi di perusahaan khususnya dalam proses penyambungan baru, ada karyawan yang melaksanakan tugas yang kurang sesuai. Staf Pemasaran dan Petugas Pelaksana diperbolehkan untuk mengubah data induk pelanggan tanpa persetujuan dari Asisten Manajer, selain itu Staf Pemasaran dan Petugas Pelaksana melaksanakan fungsi ganda sebagai fungsi penerimaan kas pada proses pasang baru, dan Staf Administrasi Keuangan juga melaksanakan fungsi ganda sebagai fungsi akuntansi.

Perbedaan antara kriteria COSO dan kondisi di perusahaan dapat mengakibatkan dampak negatif, yaitu potensi penyalahgunaan data induk pelanggan yang dapat dilakukan oleh Staf Pemasaran dan Petugas Pelaksana untuk kepentingan diri sendiri dan potensi terjadi perbedaan rekonsiliasi penerimaan kas perusahaan yang disebabkan oleh fungsi ganda yang dilaksanakan oleh Staf Pemasaran dan Petugas Pelaksana dengan staf Administrasi Keuangan. Untuk meningkatkan kinerja perusahaan, disarankan agar perusahaan melakukan penyesuaian dan meningkatkan proses pelaksanaan internal control pada proses pemasangan baru.

Dalam kriteria 5: pemantauan, internal control yang diterapkan perusahaan telah sesuai dengan kriteria COSO bahwa proses pemantauan dilaksanakan oleh personil yang tepat yang dapat memperkirakan kualitas pengendalian intern sepanjang waktu, mengevaluasi apakah telah dilaksanakan sepanjang waktu, dan memodifikasi sesuai dengan perubahan kondisi.

\section{Evaluasi Pelaksanaan Good Corporate Governance dan Kesesuaian dengan KNKG}

Pelaksanaan GCG perusahaan diterapkan pada Integritas Layanan Publik (ILP). Dalam evaluasi pelaksanaan GCG tersebut dibandingkan dengan prinsip-prinsip GCG yang ditetapkan oleh KNKG. Berdasarkan evaluasi, pelaksanaan GCG telah berjalan dengan baik sesuai dengan prinsipprinsip KNKG. Hasil evaluasi terbagi dalam beberapa prinsip.

Dalam prinsip transparan (transparency), berdasarkan keputusan Menteri Negara BUMN nomor Kep-117/m-mbu/2002, tanggal 31 Juli 2002, transparan adalah menyediakan informasi yang material dan relevan dengan cara yang mudah diakses dan dipahami oleh pemangku kepentingan. Dari wawancara diketahui bahwa untuk menjaga pelaksanaan prinsip transparan perusahaan menggunakan jasa Internal Auditor, Independent Auditor, dan BPK dan keterbukaan informasi yang disajikan dalam website perusahaan terutama dalam pelaksanaan ILP.

Dalam prinsip akuntabilitas (accountability), menurut KNKG, prinsip akuntabilitas terkait dengan pengawasan yang efektif dan kepatuhan terhadap hukum. Prinsip akuntabilitas telah dilaksanakan perusahaan dengan baik karena kegiatan usaha perusahaan telah melandaskan kepada ketentuan perundang-undangan yang berlaku, antara lain UU No. 40 tahun 2007. Selain itu perusahaan memiliki Code of Conduct (COC). Berdasarkan COC tersebut seluruh anggota wajib berkeyakinan akan memberikan kehidupan yang lebih baik bagi masyarakat, yang dapat terwujud jika anggota mencintai pekerjaannya, bangga atas pekerjaannya, menghargai sesama, dan puas atas pekerjaannya. 
Dalam prinsip responsibilitas (responsibility), sesuai dengan keputusan Menteri Negara BUMN nomor Kep-117/m-mbu/2002, tanggal 31 Juli 2002, responsibility adalah suatu tindakan perusahaan dalam melaksanakan tanggung jawab kepada masyarakat dan lingkungan sekitarnya. Tanggung jawab perusahaan terhadap masyarakat dan lingkungan dinamai Program Kemitraan dan Bina Lingkungan (PKBL). Program Kemitraan (PK) yang dilaksanakan perusahaan adalah meminjamkan modal kepada usaha kecil dan koperasi. Kegiatan ini dimulai dari tahun 1991 dan sampai dengan triwulan III tahun 2010 perusahaan telah menyalurkan dana sebesar Rp. 12.931.055.280,00 kepada 1.461 mitra binaan yang tersebar di DKI Jakarta dan Kabupaten Tangerang.

Sedangkan untuk program Bina Lingkungan (BL), perusahaan telah mengeluarkan dana sebesar Rp. 1.563.501.050,00. Dana tersebut digunakan untuk membantu biaya operasional Lembaga Swadaya Masyarakat, membantu anak-anak tidak mampu sekolah dengan memberikan sarana/perlengkapan sekolah, memberikan beasiswa kepada anak di lingkungan perusahaan, membantu sarana ibadah, bantuan sembako di bulan Ramadhan kepada warga sekitar lokasi perusahaan, membantu korban bencana alam di Mentawai, membantu korban meletusnya Gunung Merapi di Yogyakarta, dan meningkatkan kelestarian alam dengan cara melakukan penanaman pohon.

Dalam prinsip independensi (independency), independen adalah pelaksanaan tugas secara professional tanpa ada benturan kepentingan. Kemandirian merupakan hal yang wajib dilaksanakan, agar setiap organ perusahaan dapat mengambil keputusan dengan baik, serta saling menghargai, dan memahami wewenang dan tanggung jawab masing-masing dalam melaksanakan tugasnya. Pelaksanaan prinsip independensi meliputi independensi terhadap pemerintah dan independensi antar karyawan, namun setiap anggota perusahaan diwajibkan mendahulukan kepentingan bersama dibandingkan kepentingan pribadi.

Dalam prinsip kewajaran dan kesetaraan (fairness), perusahaan harus senantiasa memperhatikan hak setiap stakeholders. Fairness adalah kesetaraan dalam memenuhi hak-hak stakeholders. Pelaksanaan prinsip fairness di perusahaan adalah: (1) perlindungan wewenang General Manager, GM adalah pemegang kekuasaan tertinggi di perusahaan dengan kewenangan menetapkan alokasi anggaran, mengesahkan rotasi, mutasi, pemberian reward dan punishment kepada karyawan, menandatangani kontrak dengan mitra kerja dan mengesahkan transaksi keuangan; (2) perlindungan hak karyawan, setiap karyawan memiliki hak yang sama yang dilindungi oleh peraturan PT PLN (Persero); (3) perlindungan hak konsumen, konsumen sebagai pemangku kepentingan juga memiliki hak untuk memperoleh informasi yang akurat dan memberi kritik dan sasaran.

Berdasarkan kuesioner mengenai COC, Conflict Of Interest (COI), pengambilan keputusan, dan hak stakeholders yang diberikan kepada 30 responden yang seluruhnya karyawan perusahaan, yang kemudian diolah menggunakan skala rating scale diperoleh hasil seperti pada Gambar 1. 
Tabel 1 Analisis hasil kuesioner

\begin{tabular}{cccccccc}
\hline & \multicolumn{7}{c}{ BOBOT } \\
\hline Indikator & SS & S & KS & TS & STS & Responden & Nilai \\
\hline P-1 & 90 & 40 & 6 & 0 & 0 & 30 & 136 \\
P-2 & 85 & 52 & 0 & 0 & 0 & 30 & 137 \\
P-3 & 110 & 32 & 0 & 0 & 0 & 30 & 142 \\
P-4 & 65 & 48 & 15 & 0 & 0 & 30 & 128 \\
P-5 & 80 & 48 & 6 & 0 & 0 & 30 & 134 \\
P-6 & 85 & 52 & 0 & 0 & 0 & 30 & 137 \\
P-7 & 60 & 48 & 18 & 0 & 0 & 30 & 126 \\
P-8 & 70 & 44 & 15 & 0 & 0 & 30 & 129 \\
P-9 & 50 & 60 & 15 & 0 & 0 & 30 & 125 \\
P-10 & 80 & 48 & 6 & 0 & 0 & 30 & 134 \\
P-11 & 70 & 60 & 3 & 0 & 0 & 30 & 133 \\
P-12 & 50 & 60 & 15 & 0 & 0 & 30 & 125 \\
P-13 & 60 & 44 & 3 & 0 & 0 & 30 & 107 \\
P-14 & 55 & 68 & 6 & 0 & 0 & 30 & 129 \\
P-15 & 80 & 44 & 9 & 0 & 0 & 30 & 133 \\
P-16 & 75 & 48 & 9 & 0 & 0 & 30 & 132 \\
P-17 & 75 & 28 & 24 & 0 & 0 & 30 & 127 \\
P-18 & 100 & 40 & 0 & 0 & 0 & 30 & 140 \\
P-19 & 70 & 48 & 18 & 0 & 0 & 30 & 136 \\
P-20 & 60 & 72 & 0 & 0 & 0 & 30 & 132 \\
Total & 1.470 & 984 & 168 & 0 & 0 & 30 & 2.622 \\
\hline
\end{tabular}

Keterangan:

P-1 : Perusahaan memiliki COC

P-2 : COC didistribusikan kepada seluruh karyawan

$\mathrm{P}-3$ : COC berisi peranan setiap karyawan

P-4 : Setiap karyawan wajib mengikuti aturan COC

P-5 : Masyarakat berhak untuk menerima informasi mengenai produk perusahaan

P-6 : Perusahaan transparan dalam menerbitkal laporan keuangan

P-7 : Laporan keuangan diserahkan ke PT PLN (Persero) Pusat dengan tepat waktu

P-8 : GM tidak memiliki hak untuk mempengaruhi karyawan

P-9 : KAP dipilih berdasarkan Conflict of Interest

P-10 : Perusahaan melaksanakan aturan kepentingan bersama diatas kepentingan pribadi

P-11 : Perusahaan dan mitra kerja bekerja secara professional

P-12 : Diperbolehkan pemberian hadiah kepada mitra kerja

P-13 : Pemberian pelatihan kerja kepada karyawan

P-14 : Struktur organisasi sudah cukup kuat untuk jangka panjang

P-15 : Tanggung jawab perusahaan terhadap lingkungan sekitar lokasi kegiatan

P-16 : Melakukan evaluasi terhadap kinerja karyawan

P-17 : Hak-hak stakeholders dilindungi oleh perusahaan

P-18 : Setiap karyawan mendapat reward dan punishment yang sama

P-19 : Pemberian bonus kepada karyawan dilakukan secara transparan

P-20 : PKBL dilaksanakan secara teratur

P-21 : Kebebasan konsumen dalam menyampaikan kritik dan saran

P-22 : Pemberian motivasi kepada setiap karyawan

P-23 : Komunikasi antar karyawan terjalin dengan baik

P-24 : Hubungan perusahaan dengan lingkungan sekitar lokasi kegiatan

P-25 : PKBL dapat meningkatkan citra perusahaan 
Untuk setiap pertanyaan, diberi bobot tertinggi yaitu 5, dan bobot terendah adalah 1 . Nilai tertinggi kuesioner adalah 3.750, nilai terendah adalah 750. Berdasarkan kuisioner tersebut perusahaan mendapatkan total nilai sebesar 2.622. Dari hasil tersebut, pandangan anggota perusahaan terhadap pelaksanaan GCG adalah sebesar (2.622/3.750) x $100 \%=70 \%$. Dengan demikian pelaksanaan GCG sudah dianggap cukup baik oleh karyawan PT PLN (Persero) Distribusi Jakarta Raya dan Tangerang.

\section{Permasalahan dan Rekomendasi}

Meskipun cukup baik, namun dari analisa yang dilakukan masih terdapat beberapa kekurangan dalam pelaksanaan GCG di perusahaan yang perlu diperbaiki. (1) Kurangnya sosialisasi website PT PLN (Persero) Distribusi Jakarta Raya dan Tangerang sehingga masih banyak pelanggan yang belum mengetahui informasi pelayanan yang diberikan oleh Persero. Untuk meningkatkan kepedulan masyarakat disarankan agar perusahaan melakukan sosialisasi website tersebut kepada masyarakat. serta memberikan penyuluhan atau menyebarluaskan informasi mengenai prosedur melalui media-media massa seperti televisi, radio, atau surat kabar.

Ketidaktahuan masyarakat mengenai prosedur penggunaan jasa dan produk perusahaan serta kebiasaan masyarakat yang ingin serba instan/cepat, tidak ingin mengikuti prosedur menyebabkan masyarakat lebih menyukai untuk menggunakan jasa calo. Selain kurangnya sosialisasi, hal tersebut juga disebabkan oleh rasio jumlah petugas yang tidak sebanding dengan jumlah pelanggan yang dilayani. Jumlah pelanggan PT PLN (Persero) Distribusi Jakarta Raya dan Tangerang hingga akhir tahun 2010 adalah 3.720 .664 pelanggan, sedangkan jumlah total petugas loket adalah 175 orang yang tersebar di 35 Area Pelayanan (AP).

Untuk meningkatkan rasio tersebut dan mengurangi potensi penggunaan jasa calo, perusahaan dapat membentuk tim di seluruh area pelayanan dan memberikan pelatihan kepada para petugas di area pelayanan, sehingga pelayanan lebih baik dan lebih cepat serta mempertimbangkan mengembangkan layanan online melalui internet agar masyarakat dapat melakukan transaksi sendiri tanpa harus datang ke loket pelayanan.

(2) Petugas memberikan harga khusus kepada orang/kelompok tertentu. Hal ini biasanya terjadi pada petugas frontliner, mereka melakukan tindakan tersebut karena kurangnya komunikasi antara GM dengan petugas frontliner mengenai GCG, sehingga mereka tidak dapat menerapkan prinsip-prinsip GCG di dalam pekerjaan mereka. Sebenarnya PT PLN (Persero) Distribusi Jakarta Raya dan Tangerang telah merancang bentuk pengendalian yang cukup baik, yaitu apabila ada yang melihat seorang petugas memberikan harga khusus kepada orang/kelompok tertentu, hal ini bisa dilaporkan dengan cara mengirimkan SMS ke 8123. Namun, hal tersebut tidak berjalan dengan baik karena perusahaan kurang melakukan sosialisasi dan rendahnya kepedulian masyarakat. Upaya meningkatkan pengawasan harus dilakukan untuk menghindari terjadinya hal-hal yang tidak diinginkan. Selain itu, GM diharapkan mampu melakukan komunikasi yang baik kepada petugas frontliner mengenai prinsip-prinsip GCG agar para petugas frontliner pasti dapat melaksanakan tugasnya sesuai COC.

(3) Berdasarkan hasil kuesioner, karyawan menyetujui pemberian/penerimaan hadiah dari mitra kerja, dan pemilihan Kantor Akuntan Publik (KAP) berdasarkan benturan kepentingan dan hal yang subjektif. Berdasarkan prinsip GCG yang ditetapkan oleh KNKG, pemberian/penerimaan hadiah dari mitra kerja dan pemilihan KAP berdasarkan COI merupakan hal yang tidak diperbolehkan, karena ini dapat mengganggu independensi karyawan dan KAP. Upaya internalisasi prinsip-prinsip GCG perlu dilakukan kepada seluruh karyawan, sehingga karyawan dapat memahami bahwa pemberian/penerimaan hadiah dari mitra kerja adalah tindakan yang berpotensi mengganggu independensi dan tidak sesuai dengan prinsip GCG. 


\section{PENUTUP}

Berdasarkan evaluasi yang dilakukan diketahui bahwa dari lima komponen internal control yang ditetapkan oleh COSO, hanya satu komponen internal control yang diterapkan perusahaan yang belum sesuai dengan kriteria yang ditetapkan oleh COSO. Kekurangan internal control pada proses pemasangan baru adalah pelaksanaan fungsi ganda dan tidak ada batasan data yang dapat diubah oleh Staf Pemasaran dan Petugas Pelaksana (Sar-PP) tanpa otorisasi dari Asisten Manajer. Kekurangan ini dapat berakibat buruk pada kegiatan pemasangan baru apabila tidak diperbaiki secepatnya. Pelaksanaan GCG di PT PLN (Persero) Distribusi Jakarta Raya dan Tangerang telah berjalan dengan baik. Seluruh karyawan diwajibkan untuk menaati Code of Conduct (COC) yang telah ditetapkan oleh PT PLN (Persero) Pusat untuk meningkatkan GCG sehingga tercapai visi PT PLN (Persero) Distribusi Jakarta Raya dan Tangerang, yaitu menjadi World Class Services di tahun 2012. Namun, berdasarkan hasil kuesioner, karyawan menganggap bahwa pemberian atau penerimaan hadiah dari mitra kerja dan pemilihan KAP berdasarkan Conflict of Interest (COI) merupakan hal yang wajar. Sebenarnya pemberian/penerimaan hadiah dari mitra kerja dan pemilihan Kantor Akuntan Publik (KAP) berdasarkan COI tidak diperbolehkan karena hal tersebut dapat merusak independensi PT PLN (Persero) Distribusi Jakarta Raya dan Tangerang, independensi mitra kerja dan independensi KAP. Hal tersebut merupakan kekurangan dari pelaksanaan GCG di PT PLN (Persero) Distribusi Jakarta Raya dan Tangerang.

\section{Saran}

Beberapa saran yang direkomendasikan untuk meningkatkan pelaksanaan internal control dan GCG di PT PLN (Persero) Distribusi Jakarta Raya dan Tangerang adalah: (1) antara pemimpin dengan pelaksana sebaiknya harus sering mengadakan koordinasi yang lebih baik dalam mengerjakan pekerjaan, sehingga terjadi komunikasi yang baik terarah; (2) memisahkan database dan data umum yang dapat diakses oleh pemimpin dengan pelaksana; (3) mengadakan pelatihan atau training serta internalisasi prinsip-prinsip GCG kepada seluruh karyawan; dan (4) perlu dilakukan sosialisasi sarana informasi, seperti website perusahaan, informasi melalui media cetak dan elektronik sehingga pelanggan memahami jasa dan prosedur pelayanan jasa yang diberikan perusahaan.

\section{DAFTAR PUSTAKA}

Arens, A. A., Elder, R. J., \& Beasley, M. S. (2003). Auditing and assurance services an integrated approach, (9th ed.). Prentice Hall.

Boynton, W. C., Johnson, R. N., \& Kelly, W.G. (2003). Modern auditing buku 1 (7th ed.). (P. A. Rajoe, G. Gania, \& I. S. Budi (terj.). Jakarta: Erlangga. 